\title{
OS “ÚLTIMOS DIAS” DO ACAMPAMENTO DE IMIGRANTES E REFUGIADOS DE CALAIS
}

\section{THE “LAST DAYS” OF THE MIGRANT AND REFUGEE CAMP OF CALAIS}

\author{
Jameson Vinicius Martins da Silva ${ }^{1}$ \\ Augusto Veloso Leão ${ }^{2}$
}

\begin{abstract}
Resumo: Este relato descreve uma visita de pesquisa aos acampamentos de imigrantes e refugiados de Calais e de Norrent-Fontes, ambos localizados no departamento de Pas-de-Calais, região norte da França, entre os dias 19 e 20 de setembro de 2016. A visita ocorreu alguns dias antes que o governo francês realizasse o desmantelamento do acampamento de Calais, também conhecido como a "Selva de Calais" (Jungle de Calais), em 26 de outubro de 2016. Após apresentar brevemente o histórico dos acampamentos, descrevemos nossas impressões das visitas. Ao final, descrevemos a situação atual dos acampamentos.
\end{abstract}

Palavras-chave: direitos humanos; migração; refugiados; União Europeia.
Abstract: This article describes a research visit to the Calais and Norrent-Fontes immigrant and refugee camps, both located in the department of Pas-de-Calais, northern France, between September 19th and 20th, 2016. The visit took place a few days before the French government carried out the dismantling of the Calais camp, also known as the "Jungle of Calais" (Jungle de Calais), on October 26th, 2016. After briefly presenting the history of the camps, we describe our impressions of the visits and discuss their current situation.

Key-words: human rights; migration; refugees; European Union.

\section{Introdução}

Em julho de 2016, o Grupo de Pesquisa em Políticas Locais de Migração do Projeto Cosmópolis, do Instituto de Relações Internacionais da Universidade de São Paulo (IRIUSP), organizou a mesa de debate "Resistências locais às políticas securitárias nacionais", uma atividade autogestionada no Fórum Social Mundial das Migrações 2016, realizado em São Paulo. Durante essa atividade - na qual se debateu as formas de organização da sociedade civil e de autoridades locais que oferecem alternativas às políticas securitárias e restritivas dos movimentos migratórios no âmbito nacional - estabeleceu-se o contato

\footnotetext{
${ }^{1}$ Mestre em Relações Internacionais pelo Instituto de Relações Internacionais (IRI) da Universidade de São Paulo (USP), membro do projeto de Extensão Cosmópolis e do Grupo de Pesquisa de Políticas Locais de Migração. ORCID ID: https://orcid.org/0000-0002-2881-4490. Link para o Currículo Lattes: http://lattes. cnpq.br/3289548643736086. Contato: jameson.silva@usp.br.

${ }^{2}$ Doutor em Relações Internacionais pelo IRI-USP, membro do projeto de Extensão Cosmópolis e do Grupo de Pesquisa de Políticas Locais de Migração. Apoiado pela Fundação de Amparo à Pesquisa do Estado de São Paulo (Fapesp), pelo processo 2016/08934-0. ORCID ID: https://orcid.org/0000-0003-0036-4982. Link para o Currículo Lattes: http://lattes.cnpq.br/0297839466524263. Contato: augustovl@usp.br.
} 
entre os pesquisadores do grupo de pesquisa e Nan Thomas, ativista da organização Terre d'errance - que atua na defesa dos direitos e no suporte aos migrantes em trânsito em Pasde-Calais e no acampamento de Norrent-Fontes ${ }^{3}$. A partir deste contato, a Terre d'errance convidou os pesquisadores Jameson Silva e Augusto Leão para conhecer os acampamentos de migrantes e refugiados de Pas-de-Calais e para apresentar os resultados preliminares da pesquisa "Perfil dos imigrantes usuários de serviços públicos do Município de São Paulo"* em um debate com os voluntários participantes da rede de voluntários da organização.

A Terre d'errance atua desde 2007 na região de Norrent-Fontes na ajuda humanitária aos migrantes em trânsito, na defesa dos direitos humanos das pessoas imigrantes e daqueles que os apoiam, e na informação e sensibilização da opinião pública sobre o tema das migrações internacionais. A partir do aumento do fluxo de imigrantes e refugiados entre março de 2015 e março de 2016 no norte da França, a atuação dessa associação se tornou mais destacada na região. Em março de 2016, um acordo entre a União Europeia (UE) e a Turquia foi assinado para apoiar a construção e manutenção de centros de recepção de migrantes neste país (especialmente para a recepção de refugiados sírios), para processar os pedidos de refúgio na Turquia e também para acelerar o retorno de pessoas detidas em travessia entre a Turquia e a Grécia ${ }^{5}$. Com isso, o fluxo de pessoas entrando na UE diminuiu, porém milhares de refugiados que estavam com seus pedidos em análise, que tiveram seus pedidos inicialmente negados ou que tentavam a travessia para o Reino Unido continuavam acampados na região de Pas-de-Calais em setembro de 2016.

A visita à organização Terre d'errance ocorreu entre os dias 19 e 20 de setembro de 2016. No dia 19, os pesquisadores visitaram o acampamento de Norrent-Fontes e participaram do debate "La politique municipale pour la population migrante à São Paulo». No dia 20, os pesquisadores visitaram o acampamento de refugiados de Calais. As seções seguintes apresentam um breve histórico dos acampamentos de migrantes no

\footnotetext{
${ }^{3}$ Os acampamentos de migrantes de Calais e Norrent-Fontes abrigam pessoas com situações migratórias diversas. A grande maioria delas migrou por conta de algum tipo de perseguição política, social ou por conta de situações econômicas adversas em seus países de origem; porém, mesmo entre esses grupos, muitas pessoas não são consideradas elegíveis para requerer o refúgio segundo a legislação da União Europeia (UE) - se o solicitante tiver passado por um país considerado seguro pela UE em seu caminho, por exemplo. Como fator complicador, como se verá adiante, uma parte dos que têm direito ao refúgio preferem não dar entrada no pedido nos países em que entraram na UE, em uma tentativa de realizar o pedido em um país determinado.

${ }^{4}$ Esta pesquisa é apresentada no relatório Migrantes em São Paulo: diagnóstico do atendimento à população imigrante no município e perfil dos imigrantes usuários de serviços públicos, realizada pelo Projeto Cosmópolis do IRI-USP e pela Coordenação de Políticas para Imigrantes da Prefeitura Municipal de São Paulo (SÃO PAULO COSMÓPOLIS, 2017).

${ }^{5} \mathrm{O}$ acordo UE-Turquia representou um esforço de contenção do fluxo crescente de potenciais solicitantes de refúgio vindos da Síria, em guerra civil desde 2011. Em flagrante contradição com o princípio do nonrefoulement, consagrado na Convenção de Genebra sobre o Estatuto dos Refugiados, de 1951, o acordo estipulou o retorno de migrantes irregulares que tivessem chegado à Grécia pela Turquia. Além disso, o acordo previa que para cada sírio retornado à Turquia, um outro seria admitido na UE, segundo "critérios de vulnerabilidade da ONU"; a liberação de vistos para cidadãos turcos se aceleraria e haveria o financiamento inicial de 3 bilhões de euros da UE para a Turquia, a fim de subsidiar a assistência a refugiados naquele país. Segundo dados da Comissão Europeia, entre março de 2017 e março de 2018, 96 pessoas haviam sido retornadas para a Turquia, segundo as provisões do acordo. Nesse mesmo período, a chegada de novos migrantes foi reduzida em 97\%, em comparação com março de 2016 (COMISSÃO EUROPEIA, 2017).
} 


\section{relato de campo}

norte da França, descrevem as visitas aos acampamentos de Norrent-Fontes e Calais e, por fim, discutem algumas questões suscitadas pela situação atual dos acampamentos e dos migrantes na UE.

\section{Histórico}

Poucos anos após a abertura do túnel sob o Canal da Mancha ligando Folkestone, no Reino Unido, a Coquelles, na França, em 1994, também se iniciaram as tentativas de imigrantes e asilantes de atravessá-lo, buscando maior oferta de empregos no Reino Unido ou a reunião com familiares que já se encontravam naquele país. Entre 1999 e 2002, um acampamento para pessoas que tentavam a travessia foi organizado pela Cruz Vermelha em Sangatte, França, a pedido do governo francês, e serviu de abrigo para aproximadamente 65 mil pessoas durante todo o seu tempo de funcionamento (LIAGRE; DUMONT, 2005). Logo após sua instalação, o governo do Reino Unido pediu o fechamento do acampamento por considerá-lo um fator de atração de imigrantes para tentar a travessia. As tentativas de desmantelamento do acampamento causaram manifestações violentas por parte dos imigrantes e de organizações da sociedade civil preocupadas com a situação precária das pessoas acampadas. Seu desmantelamento em 2002, porém, não significou que o fluxo de pessoas cessasse, e diversos acampamentos surgiram em pequenas vilas e cidades da região de Pas-de-Calais. A principal mudança, a partir daí, foi que os acampamentos montados por imigrantes e refugiados e apoiados por organizações de voluntários locais se tornaram irregulares e, em decorrência disso, não ofereciam as condições sanitárias e de habitação mínimas que são encontradas nos acampamentos formais de refugiados ${ }^{6}$.

A organização Terre d'errance identificou seis acampamentos ativos na região de Pas-de-Calais, em 2016: Calais, Grande-Synthe, Steenvoorde, Tatinghem, Angres e Norrent-Fontes. Além disso, descrevem que as cidades do litoral norte francês com portos com ligação com o Reino Unido também possuem pequenos acampamentos, como os de Dieppe, Ouistreham, Cherbourg e Roscoff (LE CAMPS..., [2016?]).

Calais era o maior acampamento da região, também conhecido como "Selva de Calais" (Jungle de Calais). 0 acampamento recebeu um influxo muito grande de pessoas a partir do começo de 2015, especialmente pelo acirramento do conflito na Síria e das más condições de vida no Afeganistão, na Eritreia ou no Sudão, por exemplo, alcançando aproximadamente 5 mil pessoas em julho de 2015 (SANDRI, 2018, p. 69). Já no começo de 2016, a Terre d'errance estimou que aproximadamente 10 mil pessoas viviam na Selva. Mesmo depois do desmantelamento do setor sul do acampamento em março de 2016, ainda restavam aproximadamente 7 mil pessoas em Calais em setembro de 2016; dentre essas, 1.500 viviam em um acampamento oficial organizado pelo governo francês, enquanto 500 mulheres e crianças moravam no Centre Jules Ferry, um alojamento exclusivo para essa população, com condições gerais melhores que o restante do acampamento.

\footnotetext{
${ }^{6}$ Sandri assinala que as normas internacionais padrão para proteção de refugiados e organização de acampamentos estavam ausentes em Calais no período entre 2015 e 2016 (SANDRI, 2018, p. 65-66).
} 


\section{relato de campo}

Norrent-Fontes era um dos menores acampamentos da região de Pas-de-Calais, onde habitavam entre duzentas e trezentas pessoas no momento de nossa visita. Os migrantes acampados ali tentavam embarcar em caçambas de caminhões para atravessar para o Reino Unido, ou mesmo vinham para Norrent-Fontes "descansar" da aglomeração de pessoas em Calais, como descreveu uma das pessoas com quem nos encontramos.

A existência de acampamentos como os de Pas-de-Calais se deve parcialmente aos procedimentos acordados na Convenção de Dublin (assinada em 1990 e expandida em 2003 e 2013), que prevê que os países de entrada dos demandantes de refúgio seriam os responsáveis por analisar suas solicitações. Uma das críticas a essa determinação se deve ao fato de ela criar uma responsabilidade muito maior para os países fronteiriços da UE com relação à recepção de refugiados. Uma vez que está separado da Europa Continental, o Reino Unido forjou impedimentos para que o pedido de refúgio seja feito fora de seu território e, assim, diminuiu a possibilidade de receber novos pedidos a partir da entrada em vigor da Convenção de Dublin. Por esse motivo, pessoas solicitantes de refúgio começaram a montar acampamentos irregulares na tentativa de alcançar o Reino Unido e de fazer o pedido de refúgio ali. Nesse ínterim, elas evitam a qualquer custo o contato com as autoridades dos países pelos quais atravessam para não serem obrigadas a protocolar o pedido em outro país e, por consequência, não terem mais a possibilidade de ter o refúgio concedido no Reino Unido. Muitos desses imigrantes tinham, na realidade, o direito a requisitar refúgio no Reino Unido, por exemplo, nos casos em que familiares próximos já residissem no país. Sem alcançar o território britânico, no entanto, não poderiam efetuar a solicitação.

\section{Visitas}

O dia 19 de setembro amanheceu com sol e sem chuva, bem diferente do clima quase-outonal do norte da França, que é úmido e frequentemente nublado. Percorremos o caminho de quase um quilômetro do centro da cidade até o acampamento de NorrentFontes de carro em uma estrada de terra e enlameada, que é percorrida diariamente pelos moradores do acampamento. Assim que chegamos, nossos anfitriões, Nan Thomas, moradora da região e fundadora da associação Terre d'errance, e Julien, um voluntário vindo de Luxemburgo que acabava de começar o trabalho para a associação, nos explicaram que o acampamento de Norrent-Fontes tinha uma população majoritariamente masculina (como a maioria dos imigrantes e refugiados que buscam trabalho e moradia na UE) e com maior número de pessoas provenientes da Eritreia (em sua maioria, católicos ortodoxos) e do Sudão (com uma maioria de muçulmanos). Eles nos apresentaram a um grupo de jovens com idades entre 18 e 20 anos que começaram a preparar o café da manhã com as doações que chegaram alguns minutos antes de nós.

0 acampamento de Norrent-Fontes se situava em uma clareira rodeada por árvores, com plantações de um lado e uma área de descarte de material de construção do outro. De lá grande parte da matéria-prima utilizada no acampamento era recolhida: a maior 
parte das barracas receberam reforços de madeira e plástico para resistir melhor às baixas temperaturas e à umidade da região. Vimos três fileiras de barracas ao longo de dois corredores, que se abriam ao fundo para uma clareira onde estavam a mesquita improvisada e um campo aberto.

Conversando com os jovens da Eritreia, fomos convidados para a refeição: feijão cozido com tomate e pão. Estávamos todos sentados ao redor da panela, que acabava de ser retirada do pequeno fogareiro e fora colocada no chão para que todos pudessem compartilhar a refeição. Apesar de simples, a comida era bem temperada com alho e sal.

Quando terminamos de comer, mais um furgão com doações chegou e auxiliamos a transportar o carregamento de mantimentos para uma barraca protegida por uma grade improvisada. Ibrahim, um dos líderes do acampamento, nos explicou que as doações eram guardadas por representantes dos grupos das pessoas acampadas, normalmente divididos por nacionalidade, e que a divisão dos alimentos se fazia de acordo com o tamanho de cada grupo.

Depois de algum tempo com os jovens da Eritreia, avançamos um pouco no corredor para conversar com Nan, que estava reunida com um grupo de sudaneses em uma pequena praça de tábuas de madeira, ao lado de uma barraca que servia de cozinha, com uma pequena fogueira. Eles prepararam um café sudanês, com cardamomo, canela e gengibre. Um dos homens, Mohammed, nos contou que estudou medicina, fez um mestrado na Indonésia e retornou ao Sudão para trabalhar como servidor público da saúde. Relatou também que, a partir do momento em que grupos milicianos conseguiram mais força em sua região, ele se viu obrigado a tomar uma posição: continuar em seu emprego significaria demonstrar seu apoio ao governo, o que o tornaria um alvo das milícias, e ele decidiu escapar para pedir refúgio na UE. 0 relato do caminho à pé através da Líbia e da travessia de barco para a Itália é uma história bastante presente no debate público, porém escutar a descrição em primeira pessoa foi realmente impactante. Além disso, Mohammed tem uma história de vida parecida com a dos dois pesquisadores que assinam este relato, até o momento em que precisa escapar do conflito em seu país e passa a se encontrar em uma situação migratória frágil. Sua intenção era chegar ao Reino Unido para continuar seus estudos.

Logo depois do café na praça, seguimos caminhando pelo acampamento para observar as pessoas que se reuniam para a prece do meio-dia na mesquita. Enquanto alguns começavam a se arrumar, lavando as mãos e preparando-se para a prece, um grupo de jovens da Eritréia jogava futebol no espaço aberto logo ao lado da mesquita. Fomos mais uma vez convidados para tomar um café, dessa vez por Ibrahim, que nos levou a um pequeno quintal com cozinha atrás de um aglomerado de barracas. Éramos um grupo de dez pessoas entre recém-chegados ao acampamento e outras que já estavam ali por seis meses ou um pouco mais. Wail, que chegara há três meses na França, contou que era um jogador de futebol profissional e que pretendia continuar a carreira na Europa assim que possível. Antes disso, Wail precisaria se recuperar de uma tosse e de um resfriado que o acompanhavam enquanto conversávamos. 
Depois do café, nos despedimos e seguimos a pé pela estrada que leva ao centro de Norrent-Fontes para a apresentação da palestra com os voluntários do Terre d'errance, no centro paroquial da cidade. Conversamos com cerca de quinze pessoas sobre a política local de imigração de São Paulo. Foi uma oportunidade muito interessante de compartilhar experiências positivas, mas, principalmente, de discutir os desafios que ativistas nas duas cidades enfrentam para a garantia dos direitos dos imigrantes e refugiados. Os ativistas franceses reclamaram principalmente das medidas restritivas ao apoio a imigrantes e refugiados e da má vontade das administrações locais para atuar na defesa dessas populações. Em São Paulo, a maior parte das reclamações têm a ver com a própria inexistência de políticas que pudessem atender às dificuldades específicas da população imigrante para acessar direitos e serviços públicos.

No dia seguinte pela manhã, dirigimo-nos a Calais para visitar a chamada "Jungle". Fomos recebidos pelo padre Johannes, que trabalhava em uma organização de apoio aos refugiados. Depois de encontrá-lo na estação de trem, fomos até o acampamento em um carro que levava suprimentos para as organizações que atuam no local. No caminho, dezenas de placas e cartazes faziam propaganda política para Marine Le Pen, cuja plataforma política previa o acirramento do controle sobre os imigrantes e a recusa em aceitar novos demandantes de refúgio. Padre Johannes nos explicou que as pessoas decidiam ir até Calais não só para tentar a travessia para o Reino Unido, mas também porque a Selva se tornou uma espécie de local de referência onde as pessoas podem encontrar apoio para conseguir montar uma barraca e para se alimentar com um pouco mais de facilidade que em outros locais. Além disso, reduziriam suas chances de deportação e sua exposição à violência encontrada, por exemplo, na Hungria, Itália ou Romênia.

$\mathrm{Na}$ entrada do acampamento, nosso carro foi revistado pela polícia francesa, e padre Johannes nos explicou que a intenção disso é evitar a entrada de materiais que poderiam servir na construção de novas barracas. Metade do acampamento de Calais já havia sido demolido em março de 2016, mas o aumento da população não cessara no período: além do acirramento de conflitos no Oriente Médio e na África por causa da expansão do Estado Islâmico, por exemplo, a travessia a pé pela Europa Central ou de barco partindo do Norte da África através do Mar Mediterrâneo era mais propícia no verão devido às temperaturas amenas e ao mar mais calmo (FOX, 2016). 0 fluxo de imigrantes sírios, por outro lado, havia diminuído muito após a entrada em vigor do acordo da UE com a Turquia.

O acampamento estava localizado a aproximadamente cinco quilômetros do centro de Calais, em uma área próxima à entrada do porto de onde partem as balsas para Dover, no Reino Unido. A área também se situava ao lado da rodovia que ligava, de um lado, o porto de Calais e, por outro, a entrada para o Eurotúnel. As organizações de direitos humanos dos imigrantes reclamavam que o local serviu anteriormente como área de descarte de material industrial e, portanto, havia uma grande possibilidade de conter material tóxico. A população estimada da Selva no momento de nossa visita era de 9 mil pessoas, composta por sudaneses, afegãos, iraquianos (especialmente curdos) e pessoas de 17 outras nacionalidades (SANDRI, 2018, p. 69). 


\section{relato de campo}

Logo na entrada sul do acampamento, encontramos uma aglomeração de barracas de madeira e lona que não tinham sido demolidas em março por causa de sua função social: uma igreja ortodoxa etíope e sua biblioteca, e uma escola para crianças mantida por voluntários. Uma dezena de barracas estavam montadas nas laterais dessas construções maiores e serviam de moradia para as pessoas que faziam a manutenção da igreja e da escola. Uma pequena instalação a céu aberto de banheiros químicos e uma fonte de água utilizada para limpeza e banho completavam o ambiente.

Seguimos caminhando pelo espaço descampado onde, em março, estava o setor sul da Selva, até chegar a uma área de barracas maiores, que serviam como restaurantes tanto para os imigrantes quanto para os voluntários da área. Uma antena e um aglomerado de pessoas indicavam o local onde havia sinal de internet e celular, provido por uma das organizações locais. Padre Johannes nos convidou para um café no restaurante de um solicitante de refúgio do Afeganistão. 0 dono do estabelecimento nos contou que a vigilância sanitária havia fiscalizado os restaurantes da Selva em julho e os manteve fechados e vigiados por algumas semanas; mas uma decisão do tribunal administrativo de Lille em agosto de 2016 não permitiu o seu fechamento definitivo e determinou a sua reabertura ${ }^{7}$. Na opinião desse dono, os restaurantes do centro de Calais tinham aumentado as denúncias sobre os restaurantes do acampamento porque aqueles tinham perdido a clientela composta principalmente pelos voluntários que trabalham na Selva, estimados também em algumas centenas por dia, naquele momento. 0 dono do restaurante ironizou que se os restaurantes de Calais não conseguiam competir com os restaurantes improvisados do acampamento, provavelmente não teriam muita qualidade. Padre Johannes afirmou ainda acreditar que uma parte significativa da renda de Calais estivesse ligada à economia do acampamento: alimentos e roupas consumidas pelos acampados, hotéis e albergues ocupados pelos voluntários e um volume considerável de dinheiro proveniente de doações direcionadas ao acampamento. Ainda segundo ele, uma das reclamações recorrentes e contrárias ao acampamento é que Calais teria perdido parte de sua atratividade turística por causa da má fama provocada pelo acampamento. No entanto, padre Johannes opinou que a atividade industrial e o turismo na região haviam decaído muito antes de o acampamento ser formado e que a presença dos migrantes e dos voluntários significava uma relativa dinamização do comércio e dos serviços na região, embora as autoridades locais não reconhecessem essa contribuição da Selva.

Partimos do restaurante afegão, passando por um grande corredor de restaurantes e pequenas lojas, para o setor "oficial" do acampamento. Nessa área, contêineres de dois andares, separados do restante do local por grades, indicavam o local financiado pelo governo francês para as 1.500 pessoas, aproximadamente, que decidiram pedir refúgio na França (por conseguinte, desistindo de tentar atravessar para o Reino Unido)

\footnotetext{
${ }^{7}$ A prefeitura de Calais requisitou o fechamento imediato de 72 restaurantes e comércios na Selva em 10/08/2016, medida que foi negada pelo tribunal administrativo de Lille em 12/08/2016 com o argumento de que o pedido não cumpria com as condições de urgência e de utilidade requisitados pela lei e de que os restaurantes desempenhavam uma função essencial na alimentação das pessoas do acampamento (LA JUSTICE..., 2016). Em 12/10/2016, o Conselho de Estado francês anulou a decisão do tribunal de Lille após recurso da prefeitura de Calais (JUNGLE..., 2016).
} 
e aguardavam o processamento de seus pedidos. Nossa presença chamou a atenção de diversas pessoas no caminho, que nos convidavam para tomar chá ou café. Em vários momentos, nos perguntaram de onde vínhamos, e muitos pareceram surpresos ao ouvir falar do Brasil, um país com o qual não tiveram muito contato no acampamento.

$\mathrm{Na}$ parte norte da Selva situavam-se um centro médico mantido pelo governo francês e um acampamento montado para mulheres e crianças, o Centre Jules Ferry. Padre Johannes nos relatou que o acampamento poderia ser muito perigoso para esses dois grupos, especialmente pela violência sexual. Uma outra observação impressionante é que o acampamento oficial reproduzia a questão das fronteiras e do controle de pessoas, sendo separado do restante do acampamento por grades e com forte policiamento. Padre Johannes comentou que essa "fronteira" interna determinou que a repressão policial ocorresse fora dos limites do acampamento oficial, com a utilização frequente de forças de choque e de bombas de efeito moral.

Entramos no centro médico para conversar com um jovem afegão que chegara há alguns meses ao acampamento, Mohammed. Ele trabalhava com programas de prevenção de abuso de álcool e drogas em Cabul antes de decidir emigrar por via terrestre até a França, depois que foi ameaçado pela máfia local por causa de sua profissão. Ele conta que após deixar o Afeganistão e chegar à Europa Ocidental, teve notícias do acampamento de Calais e decidiu rumar para o norte da França para poder ajudar as outras pessoas acampadas por ali. Quando chegou a Calais, Mohammed precisou de ajuda médica e, logo depois, começou seu trabalho como voluntário no centro médico, tornando-se intérprete entre os profissionais de saúde e os pacientes. Naquele momento, Mohammed e o padre Johannes planejavam criar um programa de prevenção de abuso de álcool e drogas dentro da Selva a partir de suas experiências prévias.

Entramos novamente no centro do acampamento e seguimos para uma construção de madeira: uma exceção entre as barracas e as construções com lona. Era a sede das organizações voluntárias que atuavam em Calais, onde se buscava a coordenação de trabalho entre elas, com as lideranças comunitárias do acampamento (normalmente divididas por país de origem dos imigrantes) e também com as próprias autoridades francesas, especialmente a local e a regional. Nesse momento, a Selva possuía aproximadamente seis centros de coordenação que serviam também como pontos de distribuição de alimentos, roupas e calçados no acampamento. Padre Johannes nos falou sobre as dificuldades logísticas para a distribuição de doações no local. Para os calçados, por exemplo, foi necessário montar um esquema centralizado no qual as pessoas tinham que demonstrar que seus calçados estavam em mau estado para garantir que os bons calçados não se concentrassem nas mãos de poucas pessoas. As reuniões com a administração local ocorriam semanalmente e representavam uma oportunidade para os habitantes da Selva de apresentar suas demandas formalmente às autoridades. Porém a prefeitura de Calais se mostrava a cada dia mais relutante em oferecer qualquer tipo de apoio à Selva e havia diminuído sua assiduidade nessas reuniões. 


\section{relato de campo}

Por fim, padre Johannes nos levou para a parte mais a oeste do acampamento, onde um pequeno morro separava as barracas de um espaço vazio ao lado da rodovia, protegida por altas grades com cercas cortantes (o esquema de segurança fora patrocinado pelo Reino Unido, a pedido da prefeitura de Calais, que afirmou não ter recursos suficientes para manter a segurança do local de embarque do porto e do Eurotúnel). Do local elevado foi possível ver a extensão do acampamento, que naquele momento ocupava uma área de $1.200 \mathrm{~m}^{2}$ a $1.300 \mathrm{~m}^{2}$. O padre Johannes também nos contou que a Selva, apesar das condições precárias, servia como uma espécie de refúgio para alguns imigrantes: ali era possível formar uma pequena comunidade com pessoas que falavam a mesma língua e organizar formas de alimentação e acomodação menos penosas que isoladamente em outras regiões da Europa.

No caminho de volta para a entrada do acampamento, encontramos os resquícios de conflitos recentes no local: embalagens de bombas de gás e de efeito moral espalhadas pelo chão de areia. Padre Johannes nos ofereceu mais uma carona para o centro da cidade e, no caminho, passamos pela sede de sua organização. Ao retornar à estação de Calais, policiais demandavam a apresentação de documentos aos que acessavam a plataforma de embarque. Esse procedimento parecia pretender constranger os deslocamentos de migrantes que utilizavam os trens para transitar entre os diferentes acampamentos da região.

\section{0 acampamento atualmente}

A Selva de Calais foi desmantelada em outubro de 2016, o que gerou conflitos entre a polícia e os residentes no acampamento. As cenas da desocupação mostraram focos de incêndio por todo o acampamento e grupos de policiais utilizando bombas de efeito moral. Também mostraram várias pessoas que demonstravam não saber para onde ir ou ocupando as ruas da cidade de Calais. A maior parte dos acampados na Selva foram realocados em centros de recepção na França e tiveram seus pedidos de refúgio iniciados naquele país. Porém as organizações locais relataram que os outros acampamentos em Pas-de-Calais receberam várias pessoas após a desocupação da Selva e que muitas também se tornaram moradoras de rua em Paris e outras cidades francesas (MIGRANTS..., 2016).

Um ano após o desmantelamento da Selva, o Office français de l'immigration et de l'intégration declarou que 5.466 adultos e 1.952 menores de idade foram realocados para em centros de recepção no país e que $42 \%$ das pessoas que realizaram o pedido de refúgio já tinham recebido o status de refugiado (UN AN..., 2017). Por outro lado, estimativas de organizações francesas e inglesas indicavam que, no mínimo, 104 menores de idade que fizeram a travessia irregularmente para o Reino Unido em 2017 permaneciam sem ter sido localizadas pelas autoridades inglesas (BULMAN, 2017).

\section{Observações finais}

O fluxo de pessoas provenientes de áreas de conflito no Oriente Médio e Norte da África e a sua decisão de encontrar moradia em acampamentos não oficiais são fatores 
que não estão, de maneira alguma, desconectados das políticas relativas à imigração e ao refúgio nas últimas décadas na UE. Em primeiro lugar, a decisão de não processar os pedidos de refúgio fora do território europeu impele as pessoas a se arriscarem em travessias por terra ou através do Mar Mediterrâneo para alcançarem os países europeus. A maior consequência dessa decisão parece ser o aumento do lucro dos traficantes de pessoas e do risco para aquelas que decidem emigrar, sem muita eficácia para diminuir o fluxo de pessoas significativamente (CASTLES, 2006, p. 760). Em segundo lugar, as determinações do Acordo de Dublin definem que os pedidos de refúgio sejam analisados pelo país de entrada dos imigrantes. Um dos efeitos negativos da medida, por exemplo, é que, apesar de terem esse direito garantido no Acordo, na prática, as famílias que não chegaram juntas têm poucas chances de serem reunidas em um mesmo país posteriormente. A situação econômica dos países que são os destinos mais comuns de chegada (Itália e Grécia, principalmente) também é considerada inferior pelos imigrantes, o que os estimula a buscar refúgio em países nos quais acreditam que encontrarão condições mais favoráveis. Muitos imigrantes também buscam o Reino Unido pelo fato de já conhecerem a língua inglesa e acreditarem ser mais fácil integrar-se sem a necessidade de aprender uma nova língua estrangeira.

Por fim, é também imprescindível notar que a enorme maioria dos refugiados estão concentrados nos territórios fronteiriços de seus países de origem. Em 2017, as maiores populações de refugiados estavam concentradas na Turquia $(2,9$ milhões de pessoas, ou 3\% de sua população total, de 80 milhões de habitantes), no Paquistão (1,4 milhão de pessoas, ou $0,7 \%$ de sua população total, de 197 milhões de habitantes) e no Líbano (com quase 1 milhão de pessoas, ou 16\% de sua população total, de 6 milhões de habitantes)(ALTO COMISSARIADO DAS NAÇÕES UNIDAS PARA REFUGIADOS, 2016; ORGANIZAÇÃO DAS NAÇÕES UNIDAS, 2017), e os serviços de recepção de solicitantes de refúgio nesses países estavam próximos a seus limites. Apesar de uma população de 10 mil pessoas, como a que habitou a Selva em 2016, representar um desafio importante e um grupo proporcionalmente grande em relação ao total de habitantes da cidade de Calais ${ }^{8}$, em números absolutos e observados globalmente, as populações de imigrantes que se encontram na França e em outros países da UE representam uma questão perfeitamente manejável a partir de políticas que possam garantir seus direitos humanos e condições de vida satisfatórias.

A história da Jungle de Calais e de seus acampamentos adjacentes representa, em última instância, a tácita indisposição dos dirigentes da UE para conduzir uma política migratória calcada em princípios de acolhida humanitária, que o próprio continente propugnou ao longo das últimas décadas em escala internacional. AJungle e seus milhares de habitantes materializaram o impasse imposto pelo caráter populista das correntes políticas xenófobas que se proliferaram no continente nos últimos anos - haja vista o apoio, por um lado, à candidata de extrema-direita do Front National, Marine Le Pen, na

${ }^{8}$ Calais contava com uma população total de 76.751 habitantes no censo de 2015 , ou seja, os imigrantes da Selva de Calais representavam em torno de $13 \%$ da população da cidade. 


\section{relato de campo}

região de Pas-de-Calais durante as últimas eleições presidenciais francesas e, por outro, a retórica alarmista sobre o refúgio, por parte do governo do Partido Conservador britânico de David Cameron'.

Esse impasse, no entanto, não ocorreu sem custos. Segundo estimativas de um consórcio europeu de jornalistas (THE MIGRANTS' FILES, 2015), desde 2000, a UE despende anualmente em torno de 1 bilhão de euros em controles migratórios - a maior parte desses gastos relacionados à deportação de pessoas -, enquanto aproximadamente a mesma quantia é gasta pelos migrantes para tentar superar os controles securitários e alcançar o continente. Assim, ao mesmo tempo em que nutre com volumosos recursos uma indústria de segurança muito bem-sucedida, a "Fortaleza Europa" provocou a morte de 30 mil pessoas em suas linhas de fronteira até o início da década de 2010 (RODIER, 2012). Se realmente predominasse na UE a lógica da acolhida humanitária e da salvaguarda de direitos humanos universais, tal como se apresenta frequentemente nos discursos dos dirigentes do bloco, esse imensurável custo em vidas humanas poderia, em alguma medida, ser poupado. A formação e o posterior desmantelamento da Selva de Calais e o relativo sucesso da política de contenção de migrantes instaurada pelo acordo UE-Turquia são mais alguns episódios da contraditória política migratória europeia, que se orienta para beneficiar poucos, ao arrepio do direito internacional e dos mínimos padrões de solidariedade e de garantia de direitos humanos aos migrantes.

\section{Referências bibliográficas}

ALTO COMISSARIADO DAS NAÇÕES UNIDAS PARA REFUGIADOS (ACNUR). Figures at a glance. Genebra: UNHCR, 2016. Disponível em: <http://www.unhcr.org/figures-at-aglance.html>. Acesso em: 11 abr. 2018.

BULMAN, May. More than 100 child refugees missing in UK after being smuggled from Calais. The Independent, London, 22 jul. 2017. Disponível em: <http://www.independent. co.uk/news/uk/home-news/child-refugees-uk-missing-calais-smuggled-jungle-campcrisis-lorries-parliament-dubs-resettlement-a7853991.html>. Acesso em: 19 fev. 2018.

CASTLES, Stephen. Guestworkers in Europe: a resurrection? International Migration Review, New York, v. 40, n. 4, p. 741-766, 2006.

COMISSÃO EUROPEIA. EU-Turkey Statement: one year on. Bruxelas: European Commission, 2017. Disponível em: <https://ec.europa.eu/home-affairs/sites/homeaffairs/files/ what-we-do/policies/european-agenda-migration/background-information/eu_turkey_ statement_17032017_en.pdf>. Acesso em: 9 abr. 2018.

${ }^{9}$ Ver Delrue e Sénécat (2017) e Elgot (2016). 
DELRUE, Maxime; SÉNÉCAT, Adrien. Immigration et terrorisme: Marine Le Pen multiplie les intox. Le Monde, Paris, 18 abr. 2017. Disponível em: <https://www.lemonde.fr/lesdecodeurs/article/2017/04/18/immigration-et-terrorisme-marine-le-pen-multiplieles-intox_5113168_4355770.html>. Acesso em 8 abr. 2018.

ELGOT, Jessica. How David Cameron's language on refugees provoked anger. The Guardian, London, 27 jan. 2016. Disponível em: <https://www.theguardian.com/uk-news/2016/ jan/27/david-camerons-bunch-of-migrants-quip-is-latest-of-several-such-comments>. Acesso em: 8 abr. 2018.

FOX, Kara. Calais 'Jungle' migrant camp: what you need to know. CNN, Atlanta, 22 out. 2016. Disponível em: <http://edition.cnn.com/2016/10/21/europe/calais-junglemigrant-camp-explainer/index.html>. Acesso em: 19 fev. 2018.

JUNGLE de Calais: le Conseil d'Etat valide l'expulsion des commerces. Le Parisien, Paris, 12 out. 2016. Disponível em: <http://www.leparisien.fr/societe/jungle-de-calais-le-conseild-etat-valide-l-expulsion-des-commerces-12-10-2016-6198390.php>. Acesso em: 19 fev. 2018.

LA JUSTICE dit non à la fermeture des échoppes de la "jungle" de Calais. Le Parisien, Paris, 12 ago. 2016. Disponível em: <http://www.leparisien.fr/faits-divers/la-justice-dit-nona-la-fermeture-des-echoppes-de-la-jungle-de-calais-12-08-2016-6035427.php>. Acesso em 19 fev. 2018.

LES CAMPS du Nord-Pas-de-Calais. Terre d'errance, Norrent-Fontes, [2016?]. Disponível em: <https://terreerrance.jimdo.com/les-campements/>. Acesso em: 19 fev. 2018.

LIAGRE, Romain; DUMONT, Frédéric. Sangatte: vie et mort d'un centre de "réfugiés". Annales de géographie, Paris, v. 641, n. 1, p. 93-112, 2005. Disponível em: <https://www. cairn.info/revue-annales-de-geographie-2005-1-page-93.htm>. Acesso em: 12 jun. 2018.

MIGRANTS: après l'évacuation de Calais, les camps à Paris grossissent. Le Parisien, Paris, 28 out. 2016. Disponível em: <http://www.leparisien.fr/societe/migrants-apresl-evacuation-de-calais-les-camps-parisiens-grossissent-28-10-2016-6262533.php>. Acesso em: 5 abr. 2018.

ORGANIZAÇÃ̃O DAS NAÇÕES UNIDAS (ONU). Divisão de População do Departamento de Assuntos Econômicos e Sociais. World Population Prospects 2017. Genebra: ONU, 2017. Disponível em: <https://esa.un.org/unpd/wpp/DataQuery/>. Acesso em: 11 abr. 2018.

RODIER, Claire. Migrants et réfugiés: réponses aux indécis, aux inquiets et aux réticents. Paris: La Découverte, 2012.

SANDRI, Elisa. "Volunteer Humanitarianism": volunteers and humanitarian aid in the Jungle refugee camp of Calais. Journal of Ethnic and Migration Studies, Brighton, v. 44, n. 1, p. 65-80, 2018. Disponível em: <https://doi.org/10.1080/1369183X.2017.1352467>. Acesso em: 12 jun. 2018. 
SÃO PAULO COSMÓPOLIS (Org.). Imigrantes em São Paulo: diagnóstico do atendimento à população imigrante no município e perfil dos imigrantes usuários de serviços públicos. São Paulo: IRI-USP, 2017. Disponível em: <http://www.iri.usp.br/documentos/eBook\%20 Cosmopolis.pdf>. Acesso em: 12 jun. 2018.

THE MIGRANTS' FILES. The money trails: follow the money - some of it - into the subeconomy spawned by migration. [S.l.], 18 jun. 2015. Disponível em: <http://www. themigrantsfiles.com/\#/the-money-trails>. Acesso em: 12 abr. 2018.

UN AN après le démantèlement du bidonville de Calais, $42 \%$ des migrants ont obtenu l'asile. Le Monde, Paris, 20 out. 2017. Disponível em: <http://www.lemonde.fr/societe/ article/2017/10/20/un-an-apres-le-demantelement-du-bidonville-de-calais-42-desmigrants-ont-obtenu-l-asile_5203937_3224.html>. Acesso em: 19 fev. 2018.

Texto recebido em: 19de Fevereiro de 2018 Aprovado para publicação em: 07 de Março de 2018 